\title{
Response of Greenhouse Tomato to Varied Low Pre-night Temperatures at the Same Daily Integrated Temperature
}

\author{
Lu Zhang \\ State Key Laboratory of Vegetation and Environmental Change, Institute of \\ Botany, the Chinese Academy of Sciences, 20 Nanxincun, 100093, Beijing, \\ P.R. China; and Greenhouse and Processing Crops Research Centre, \\ Agriculture and Agri-Food Canada, 2585 County Road 20, Harrow, Ontario, \\ Canada NOR $1 G 0$
}

\author{
Xiuming Hao ${ }^{1}$ \\ Greenhouse and Processing Crops Research Centre, Agriculture and Agri- \\ Food Canada, 2585 County Road 20, Harrow, Ontario, Canada NOR 1 G0
}

Yonggeng Li and Gaoming Jiang

State Key Laboratory of Vegetation and Environmental Change, Institute of Botany, the Chinese Academy of Sciences, 20 Nanxincun, 100093, Beijing, P.R. China

Additional index words. Solanum lycopersicum, low temperature tolerance, temperature integration, heating, photosynthesis, greenhouse climate control, energy use efficiency

\begin{abstract}
Early production and high energy efficiency are important in greenhouse vegetable production in cold regions. A dynamic temperature integration strategy with low pre-night temperature (PNT) has been developed to reduce energy consumption and to improve early fruit yield and energy use efficiency. However, the application of this temperature control strategy is feasible only if there is no crop yield and quality loss. To determine the low PNT tolerance threshold and explore the mechanism of this temperature control strategy on plant growth and development, the effects of four PNT temperature integration treatments (PNT9, PNT11, PNT13, and PNT15, with an actual PNT of 9.4, 11.3, 13.3, and $15.1{ }^{\circ} \mathrm{C}$, respectively) on greenhouse tomatoes (Solanum lycopersicum) were investigated. The PNT was applied at the beginning of the night for $3 \mathrm{~h}$, whereas temperatures in other periods during a day $(24 \mathrm{~h})$ were adjusted accordingly to ensure the same $24-\mathrm{h}$ average temperature $\left(19.4^{\circ} \mathrm{C}\right)$ for all PNT treatments. Four cultivars (Bigdena, Clarance, Quest, and Conchita), representing all three types (beefsteak, cluster, and cherry) of greenhouse tomatoes, were used in the study. The optimum PNT for fruit yield was 13.8 and $14.9{ }^{\circ} \mathrm{C}$ for 'Bigdena' and 'Conchita', respectively. Low PNT down to $11^{\circ} \mathrm{C}$ did not compromise fruit yield and plant development in 'Clarance', and thus a PNT lower than $13{ }^{\circ} \mathrm{C}$ can be used for 'Clarance' if it does not have a negative effect on fruit quality. In 'Bigdena' and 'Conchita', the above-ground biomass increased with increasing PNT at the low range of PNT, peaked at $\approx 13^{\circ} \mathrm{C}$ PNT (13.7 and $13{ }^{\circ} \mathrm{C}$ for 'Bigdena' and 'Conchita', respectively), then declined at high PNT. Leaf photosynthesis rates were increased by the highest PNT (PNT15), whereas respiration rates were reduced by the lowest PNT (PNT9). Therefore, PNT at $\approx 13^{\circ} \mathrm{C}$ might have allowed for the proper balance between the high photosynthesis for photoassimilate generation and the low respiration for photoassimilate conservation and thus accumulated the highest photoassimilate and the highest fruit yield in 'Bigdena'. Flower development rate in 'Conchita' decreased linearly with low PNT, which might have limited the response of its fruit yield to low PNT and raised the optimum PNT for fruit yield to $14.9^{\circ} \mathrm{C}$. Temperature integration with proper low PNT can be an effective climate control strategy for increasing early fruit yield and energy use efficiency in greenhouse tomato production.
\end{abstract}

Greenhouse crop production is an important segment of the agricultural industry around the world, especially for countries in cold regions (Jensen and Malter, 1994; Wittwer and Castilla, 1995). In greenhouse crop production, the indoor climate is conditioned (such as heating) to provide a suitable growing environment for the crop to allow for off-season production, or stable, yearround production of a high-quality product (Bot, 2001). However, greenhouse crop production, especially in cold regions, usually requires a lot of energy. A large amount of fossil fuels is used for greenhouse heating, which is not only expensive (average: $\$ 130,000 /$ ha for 2005 in Canada; Statistics Canada, 2005), but also results in the emission of a significant amount of greenhouse gas $\left(\mathrm{CO}_{2}\right)$ and other air pollutants such as NOx into the atmosphere. With the rising price in the last decade, energy has become the largest cost component in greenhouse vegetable production in North America, accounting for $15 \%$ to $40 \%$ of the total production cost (Hao et al., 2008). To reduce energy cost and the emission of greenhouse gas and air pollutants into the atmosphere, there is an urgent need to develop innovative technology for cutting down energy consumption and improving energy use efficiency in greenhouse crop production.

The greenhouse climate is traditionally controlled with an aim to keep the climate at constant pre-set levels, which are assumed to be optimal for plant growth. This approach has not used the natural adaptability of plants to environmental variations to reduce energy use while maintaining crop productivity. The developmental rates of many crops are determined by long-term average temperature rather than instantaneous temperature (De Koning, 1990). Therefore, the periods of low temperature can be compensated for by periods of higher than normal temperature and vice versa. This plant's ability to integrate temperature can be used to save energy by using high air temperature when heating cost is lower (such as under sunny, calm, and warm conditions) and low air temperature when heating cost is higher (such as under cloudy, windy, and cold conditions) (Korner et al., 2004; Rijsdijk and Vogelezang, 2000) while ensuring an optimal long-term (24 h) average temperature (Chalabi et al., 1996). Annual heating cost can be reduced by $10 \%$ to $20 \%$ without any yield loss (Pollet et al., 2009; Van den Berg et al., 2001). The extent of energy savings with this temperature integration concept will depend on a crop's tolerance to low and high temperature (temperature bandwidth) and the variation in local climate; the larger bandwidth the crop can tolerate, the larger variation the local climate has, and the higher energy savings can be achieved with this temperature control concept/strategy.

High early-season yield is especially important in greenhouse vegetable production in cold regions because the market price is usually much higher before the field products can reach the market. Increasing temperature can speed up plant growth and development, which could increase early yield (Papadopoulos and Hao, 2000a). However, this may not be feasible under the low light conditions in winter; the high respiration resulting from the high temperature may exhaust the limited photoassimilates, reducing yield. Besides, high temperature settings will increase energy consumption. Luckily, most of the vegetables produced in modern greenhouses are fruit vegetables. Because fruit have less surface area per unit of volume or weight (less heat exchange area per unit of volume and thus slower temperature decline during a fast air temperature drop), higher fruit temperature 
(relative to leaf temperature) can be achieved with a low temperature pulse. A dynamic temperature integration concept/strategy with a low PNT pulse has been developed recently based on this principle (Hao et al., 2008). The temperature control concept/strategy generated higher fruit temperature (relative to leaf temperature) and promoted early fruit production with similar or less energy use (Hao et al., 2008). The exact mechanism of this dynamic temperature integration strategy on plant growth and development is still not clear. To fully achieve its potential on promotion of early fruit production and energy savings, it is critical to know the low PNT tolerance threshold of the crop. Therefore, this study was performed 1) to determine the low PNT tolerance threshold and the optimum PNT for the crop; and 2) to explore how it affects plant growth and development. Tomatoes (Solanum lycopersicum) are the most important greenhouse vegetable and also have the highest output-input energy ratio [energy in output produce (fruit)/input energy] in modern greenhouse production (Ozkan et al., 2004). Therefore, tomatoes were used as the experimental material in this study.

\section{Material and Methods}

The experiment was conducted from May to Oct. 2008 in four large (walk-in) growth chambers $(2.44 \mathrm{~m} \times 1.53 \mathrm{~m}$ in growth area; ConEnviron, Manitoba, Canada) at the Greenhouse and Processing Crops Research Center, Agriculture and Agri-Food Canada at Harrow, Ontario, Canada. Each growth chamber trial lasted $\approx 1$ month and the trial was conducted three times over time. Four cultivars that represent the three main types (beefsteak: 'Bigdena' and 'Quest', cluster: 'Clarance', and cherry: 'Conchita') of greenhouse tomatoes were used as the experimental material. Quest is a cultivar with vigorous vegetative growth, whereas 'Bigdena', 'Clarance', and 'Conchita' are cultivars with balanced vegetative and generative growth.

Tomato seeds were sown in small rockwool cubes $(3.8 \mathrm{~cm} \times 3.6 \mathrm{~cm} \times 4.0 \mathrm{~cm}$; Fibrex Insulation Inc., Sarnia, Ontario, Canada) on 9 May, 25 June, and 31 July. After seedlings emerged and cotyledons fully unfolded, the seedlings were transplanted into large rockwool blocks $(7.5 \mathrm{~cm} \times 7.5 \mathrm{~cm} \times 7.5 \mathrm{~cm}$; Fibrex Insulation Inc.). The transplants were raised on benches and flood-irrigated with stan-

\footnotetext{
Received for publication 1 Apr. 2010. Accepted for publication 20 Aug. 2010

This research was funded in part by the PeerReview Research Program of Agriculture and AgriFood Canada (AAFC). China Scholarship Council (CSC) provided financial support to the first author for the study in Canada.

We thank JingMing Zheng for his technical assistance.

The mention of trade names in this article does not imply product endorsement by the authors and their associated institutions.

${ }^{1}$ To whom reprint requests should be addressed; e-mail xiuming.hao@agr.gc.ca.
}

dard complete nutrient solution (OMAFRA, 2005) using a Harrow Fertigation Manager ${ }^{\circledR}$ (Papadopoulos and Liburdi, 1989). The transplants were planted into $3-\mathrm{L}$ pots filled with coconut dust from Coco Grow Bags (Millenniumsoils Coir, Vgrove, St. Catharines, Ontario, Canada) at the five to six leaf stage 1 week before moving the plants into the growth chambers. Four plants per cultivar were transferred into each growth chamber on 22 June, 1 Aug., and 9 Sept. After moving into the growth chambers, the plants were managed according to commercial greenhouse practices (OMAFRA, 2005). Sufficient complete nutrient solution $(2 \mathrm{~L} /$ plant $/ \mathrm{d}$, eight times $\times 7 \mathrm{~min}$ per irrigation) was delivered to the plants from a drip irrigation system to prevent any water stress or nutrient deficiency. The cluster of flowers was shaken daily with an electrical vibrator to improve pollination. After 2 weeks of temperature treatments in the growth chambers, the plants were topped at two leaves above the third cluster and each cluster was pruned to five fruit for 'Bigdena', 'Clarance', and 'Quest'. For cherry tomato 'Conchita', the plants were topped at two leaves above the fifth cluster and no cluster pruning was performed. The plants received $400 \mu \mathrm{mol} \cdot \mathrm{m}^{-2} \cdot \mathrm{s}^{-1}$ of photosynthetically active radiation $(P A R$, measured with a LI-COR 191 SB line quantum sensor; LI-COR, Lincoln, NE) at the top canopy during a 12 -h daytime (0600 to 1800 $\mathrm{HR})$. Ninety percent of the $P A R$ in the growth chambers was from cool white fluorescent lamps and 10\% from incandescent bulbs. Relative humidity in the growth chambers was maintained at $75 \%$.

Temperature treatments. Four temperature treatments [PNT9, PNT11, PNT13, and PNT15 (the control) with a PNT of 9, 11, 13, and $15{ }^{\circ} \mathrm{C}$, respectively] were implemented in the four growth chambers. The PNTs were applied just after the light was shut off for $3 \mathrm{~h}$ from 1801 to $2100 \mathrm{HR}$. The temperature settings in other periods during a day were modified based on the temperature integration concept to ensure the same $19.4{ }^{\circ} \mathrm{C}$ daily $(24 \mathrm{~h})$ average temperature for all four temperature treatments (Table 1). The temperature set points in other periods were within the range of optimal temperature for greenhouse tomatoes (De Koning, 1994; Heuvelink and Dorais, 2005; OMAFRA, 2005) to prevent any confounding effect from the temperature difference in other periods. Temperature treat- ments were implemented in the growth chambers from 22 June to 23 July, from 1 Aug. to 3 Sept., and from 9 Sept. to 10 Oct. for the three trials, respectively.

Air temperature monitoring. Four shaded copper-constantan thermocouples (type T, wire diameter $0.1 \mathrm{~mm}$; Omega, Laval, Quebec, Canada) were used to record air temperature in each growth chamber. The thermocouples were calibrated against aspirated Hycal sensors (Model IH 3602, standard sensor for air temperature measurement; Hycal Co., El Monte, $\mathrm{CA} ; \pm 0.1{ }^{\circ} \mathrm{C}$ for temperature) before they were used in the growth chambers. Readings from the sensors were logged with a CR21X data logger (Campbell Scientific Corporation, Edmonton, Alberta, Canada). The data logger scanned the sensor every $10 \mathrm{~s}$ and recorded the average values every $15 \mathrm{~min}$. The PAR inside the growth chambers was measured periodically with a 1-m long LI-COR 191 SB line quantum sensor at the top of the canopy to ensure the plants received the same intensity of light in all four growth chambers.

Leaf gas exchange measurements. Leaf gas exchanges were only evaluated at PNT9 and PNT15, the lowest and highest PNT treatments. All leaf gas exchange rates were measured on the fifth fully expanded leaf with a LI-COR 6400 portable photosynthesis system equipped with a 6400-02B lightemitting diode light source and a 6400-01 $\mathrm{CO}_{2}$ injector system (LI-COR). The system can control light, temperature, humidity, and $\mathrm{CO}_{2}$ concentration in the leaf chamber.

Light and carbon dioxide response (A-Ci) curves were determined on three plants from each of the four cultivars in each of the three trials. Light response curves were determined between 900 and $1200 \mathrm{HR}$ at the following PAR levels: 0, 20, 50, 100, 200, 500, 1000, 1500 , and $1800 \mu \mathrm{mol} \cdot \mathrm{m}^{-2} \cdot \mathrm{s}^{-1}$. During the measurements, $20 \pm 0.5^{\circ} \mathrm{C}$ leaf temperature, $400 \mu \mathrm{mol} \cdot \mathrm{mol}^{-1} \mathrm{CO}_{2}$, and $70 \% \pm 10 \%$ relative humidity were maintained inside the leaf chamber. Carbon dioxide response (A-Ci) curves were determined at the following $\mathrm{CO}_{2}$ concentrations: $50,100,200,400,600$, $800,1000,1500$, and $2000 \mu \mathrm{mol} \cdot \mathrm{mol}^{-1}$. The $P A R$ inside the leaf chamber was 400 $\mu \mathrm{mol} \cdot \mathrm{m}^{-2} \cdot \mathrm{s}^{-1}$, whereas other conditions were the same as in the measurements for light response curves.

Plant growth measurements. Plant height, internode length, flower number, and leaf

Table 1. Air temperature set points (ST) and actual temperatures (AT) in the four growth chambers for temperature integration treatments with low pre-night temperature to achieve the same daily $(24 \mathrm{~h})$ average temperature of $19.4^{\circ} \mathrm{C}$ from May to Oct. $2008 .{ }^{z}$

\begin{tabular}{|c|c|c|c|c|c|c|c|c|c|c|}
\hline \multirow{3}{*}{$\begin{array}{l}\text { Temperature } \\
\text { treatment }\end{array}$} & \multirow{2}{*}{\multicolumn{2}{|c|}{$\frac{\text { Day temp. }\left({ }^{\circ} \mathrm{C}\right)}{0600-1800 \mathrm{HR}}$}} & \multicolumn{6}{|c|}{ Night temp. $\left({ }^{\circ} \mathrm{C}\right)$} & & \\
\hline & & & \multicolumn{2}{|c|}{$1800-2100 \mathrm{HR}$} & \multicolumn{2}{|c|}{$2100-0600 \mathrm{HR}$} & \multicolumn{2}{|c|}{ Night avg } & \multicolumn{2}{|c|}{ 24-h avg $\left({ }^{\circ} \mathrm{C}\right)$} \\
\hline & ST & $\mathrm{AT}$ & ST & $\mathrm{AT}$ & ST & AT & ST & $\overline{\mathrm{AT}}$ & ST & $\mathrm{AT}$ \\
\hline$\overline{\text { PNT9 }}$ & 23.0 & 23.0 & 9.0 & 9.4 & 18.0 & 18.3 & 15.8 & 16.1 & 19.4 & 19. \\
\hline PNT11 & 22.5 & 22.4 & 11.0 & 11.3 & 18.0 & 18.3 & 16.3 & 16.6 & 19.4 & 19. \\
\hline PNT13 & 22.0 & 22.0 & 13.0 & 13.3 & 18.0 & 18.3 & 16.8 & 17.1 & 19.4 & 19.5 \\
\hline PNT15 & 21.5 & 21.4 & 15.0 & 15.1 & 18.0 & 18.1 & 17.3 & 17.4 & 19.4 & 19.4 \\
\hline
\end{tabular}

${ }^{z}$ The temperature was measured by copper-constantan thermocouples (type $\mathrm{T}$, wire diameter $0.1 \mathrm{~mm}$; Omega, Laval, Quebec, Canada), which were calibrated against the air temperature measured by the aspirated Hycal sensor (standard sensor for air temperature and humidity measurement in growth chamber and greenhouses; Hycal Co., El Monte, $\mathrm{CA} ; \pm 0.1^{\circ} \mathrm{C}$ air temperature).

$\mathrm{PNT}=$ pre-night temperature. 
number of three plants for each cultivar in each growth chamber were recorded after 2 weeks of temperature treatments, before the plants were topped. Leaf chlorophyll index of the fifth fully expanded leaf was also measured after 2 weeks of temperature treatments with a chlorophyll meter (SPAD 502; Minota, Osaka, Japan). Destructive measurements were conducted after $\approx 1$ month of temperature treatments on 23 July, 3 Sept., and 10 Oct. for the three trials, respectively. Total leaf area was measured using a LI-COR 3100 leaf area meter (LI-COR). Stem dry weight and leaf dry weight were determined after being dried in a crop drier at $65^{\circ} \mathrm{C}$ for 2 to 3 weeks. Specific leaf weight was calculated as the leaf dry weight per unit of leaf area. Fruit on the plant were removed; their number and fresh weight were recorded. The fruit were then sliced and dried in a crop drier at $65^{\circ} \mathrm{C}$ for 2 to 3 weeks to determine their dry weight. Total aboveground biomass and biomass partition to stem, leaf, and fruit were calculated. Unmarketable fruit such as those with blossom-end rot (BER) were recorded separately according to the commercial grading standards (Ontario Ministry of Agriculture, Food and Rural Affairs, 2004).

Data analysis. Data were analyzed based on the means of three plants for each cultivar in each of the three trials using the General Linear Models Procedure in the SAS package (SAS statistical analysis package version 9.0; SAS Institute, Inc., Cary, NC). Analysis of variance (ANOVA) was first conducted. If the treatment effect was significant $(P \leq$ $0.05)$, then the treatment means were separated with a least significant difference test. A regression analysis was conducted when the $P$ value for PNT effects in the ANOVA was $<$ 0.20 . Regression equations based on a polynomial model were fitted with the backward elimination method. To avoid loss of any important model term, $\alpha=0.15$ was used as a critical level to determine whether a model term should be dropped from the model during the fitting process. The partial $R^{2}$ for PNT $\left(R_{t}^{2}\right)$, which measures the strength of the relationship between the response and temperature treatments after being adjusted for replication (block) effects, was calculated for the final regression. Significance of $R_{\mathrm{t}}^{2}$ was determined by an $\mathrm{F}$ test (Papadopoulos and Hao, 2000b). Only significant $(P \leq 0.05)$ regression equations are reported. The optimum PNT for the maximum or minimum values in plant growth parameters was calculated by solving the first derivative of their corresponding quadratic regression equations as Diaz-Perez and Batal (2002).

Photosynthesis curves were fitted with a photosynthesis assistance program (Dundee Scientific, Dundee, U.K.). ANOVA on the variables of photosynthetic curves was also performed using the General Linear Models Procedure in the SAS package.

\section{Results and Discussion}

Actual air temperature. The air temperature targets for the four PNT treatments were precisely achieved in the four growth chambers except for some minor deviations ( 0.1 to $0.4{ }^{\circ} \mathrm{C}$ ) during the night (Table 1). Most of the deviations were within the margin of errors for air temperature measurements $\left( \pm 0.1^{\circ} \mathrm{C}\right)$.

Photosynthetic capacity. The photosynthetic capacity of all cultivars was in general reduced by the PNT9 treatment (Table 2). The maximum net photosynthetic rate at $\mathrm{CO}_{2}$ saturation $\left(\mathrm{A}_{\mathrm{sat}}\right)$ was significantly reduced by PNT9 in all four cultivars. The reduction in the maximum net photosynthetic rates at light saturation $\left(\mathrm{A}_{\max }\right)$ was also significant in 'Bigdena' and 'Conchita' but it was not in 'Quest' and 'Clarance' as a result of the difference between cultivars. Dark respiration $(\mathrm{R})$ and respiration during the daytime $\left(\mathrm{R}_{\mathrm{day}}\right.$, including both dark respiration and photorespiration) at PNT9 was in general lower than at PNT15. The dark respiration, especially the maintenance respiration, is responsible for most of the photoassimilate consumption. Therefore, the impact of low PNT on leaf gas exchanges was not always negative; the reduction in respiration could allow the plants to conserve more photoassimilates.

Plant growth and development. The PNT treatments did not affect plant height (Table 3 ) and internode length (same trend as plant height, data not shown). A lot of research has been conducted to investigate the effects of day temperature, night temperature, and daynight temperature difference (DIF) on plant height and internode length (De Koning, 1992; Papadopoulos and Hao, 2000a). Plant height and internode length of tomatoes are usually increased with increasing DIF (De Koning, 1992). In previous research, a constant night (dark period) temperature was used. In this study for dynamic temperature control, the low PNT was only applied during the first $3 \mathrm{~h}$ of a dark period (night), whereas the temperature during the rest of the night was the same among the treatments (Table 1). Although the PNT difference between the lowest PNT (PNT9) and the highest PNT (PNT15) treatment was $6{ }^{\circ} \mathrm{C}$, the DIF (difference between the daytime average and

Table 2. Leaf gas exchange parameters of four tomato cultivars grown under different temperature treatments. $^{\mathrm{z}}$

\begin{tabular}{llcccc}
\hline Cultivar & Treatment & $\begin{array}{c}\mathrm{A}_{\max } \\
\left(\mu \mathrm{mol} \cdot \mathrm{m}^{-2} \cdot \mathrm{s}^{-1}\right)\end{array}$ & $\begin{array}{c}\mathrm{R} \\
\left(\mu \mathrm{mol} \cdot \mathrm{m}^{-2} \cdot \mathrm{s}^{-1}\right)\end{array}$ & $\begin{array}{c}\mathrm{A}_{\mathrm{sat}} \\
\left(\mu \mathrm{mol} \cdot \mathrm{m}^{-2} \cdot \mathrm{s}^{-1}\right)\end{array}$ & $\begin{array}{c}\mathrm{R}_{\text {day }} \\
\left(\mu \mathrm{mol}^{-2} \cdot \mathrm{m}^{-2} \cdot \mathrm{s}^{-1}\right)\end{array}$ \\
\hline Bigdena & PNT9 & $19.4 \mathrm{~b}$ & $0.64 \mathrm{~b}$ & $20.4 \mathrm{~b}$ & $6.5 \mathrm{a}$ \\
& PNT15 & $25.3 \mathrm{a}$ & $1.21 \mathrm{a}$ & $25.3 \mathrm{a}$ & $7.2 \mathrm{a}$ \\
Quest & PNT9 & $19.7 \mathrm{a}$ & $1.07 \mathrm{~b}$ & $19.5 \mathrm{~b}$ & $5.4 \mathrm{a}$ \\
& PNT15 & $21.1 \mathrm{a}$ & $1.41 \mathrm{a}$ & $21.8 \mathrm{a}$ & $6.3 \mathrm{a}$ \\
Clarance & PNT9 & $27.1 \mathrm{a}$ & $1.61 \mathrm{a}$ & $26.2 \mathrm{~b}$ & $7.5 \mathrm{~b}$ \\
& PNT15 & $28.4 \mathrm{a}$ & $1.78 \mathrm{a}$ & $29.2 \mathrm{a}$ & $11.3 \mathrm{a}$ \\
& PNT9 & $25.6 \mathrm{~b}$ & $1.88 \mathrm{a}$ & $28.7 \mathrm{~b}$ & $9.6 \mathrm{~b}$ \\
& PNT15 & $29.1 \mathrm{a}$ & $1.80 \mathrm{a}$ & $31.7 \mathrm{a}$ & $11.1 \mathrm{a}$ \\
LSD $_{0.05}{ }^{\mathrm{y}}$ & & 2.2 & 0.29 & 2.2 & 1.1 \\
\hline
\end{tabular}

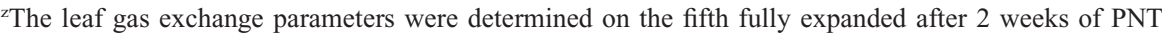
treatments ( 8 weeks after seeding).

$\mathrm{A}_{\max }=$ the maximum net photosynthetic rate at light saturation; $\mathrm{R}=$ dark respiration when light intensity was zero; $\mathrm{A}_{\mathrm{sat}}=$ the maximum net photosynthetic rate at $\mathrm{CO}_{2}$ saturation; $\mathrm{R}_{\text {day }}=$ respiration at $0 \mu \mathrm{mol} \cdot \mathrm{mol}^{-1}$ of $\mathrm{CO}_{2}$ and $400 \mu \mathrm{mol} \cdot \mathrm{m}^{-2} \cdot \mathrm{s}^{-1}$ photosynthetically active radiation $(P A R)$; the different letters following treatment means indicate a significant difference $(P \leq 0.05)$.

${ }^{\mathrm{y}} \mathrm{LSD}_{0.05}=$ the least significant difference at $\alpha=0.05$.

$\mathrm{PNT}=$ pre-night temperature. night average) between them was less than $2{ }^{\circ} \mathrm{C}$ (Table 1). Therefore, the plant height and internode length of tomatoes was more likely determined by the difference between daytime average and night average instead of stantaneous temperature.

Leaf number was also unaffected by the PNT treatments (Tables 3). This is in agreement with the findings in previous research mined by long-term average rather than instantaneous temperature as long as the temperature fluctuates within a suitable bandwidth (De Koning, 1990; Hurd and temperature integration had similar $24-\mathrm{h}$ average temperature (Table 1) and thus no effect leaf number.

The PNT treatments did not affect leaf area (Table 3). However, they did affect leaf chlorophyll in 'Clarance' and 'Bigdena' (as 'Conchita' and 'Clarance' (as demonstrated by a significant regression on PNT in Table 3). Therefore, PNT treatments did not affect photosynthetic area but the photosynarea. The specific leaf weight increased with increasing PNT at the low range of PNT, peaked at $\approx 13{ }^{\circ} \mathrm{C}$ PNT, and then declined at high PNT in 'Conchita' (Table 3). Leaf photoPNT (PNT15), whas inces reduced by the lowest PNT (PNT9; Table 2). The increase in specific leaf weight with increasing PNT at low range of PNT was most as PNT15) might be the result of excessive respiration. Therefore, PNT at $\approx 13{ }^{\circ} \mathrm{C}$ might have allowed for the proper balance between generation (photosynthesis) highest photoassimilate accumulation in leaves in some cultivars such as 'Conchita'.

There was a significant interaction between the cultivars and PNT treatments on capacity, wher the decline at high PNT (such 
Table 3. Plant growth and development parameters of four tomato cultivars grown with different temperature treatments. ${ }^{\mathrm{z}}$

\begin{tabular}{|c|c|c|c|c|c|c|c|c|c|}
\hline \multirow[b]{2}{*}{ Cultivar } & \multirow[b]{2}{*}{ Treatment } & \multicolumn{4}{|c|}{ After 2 weeks of PNT treatments } & \multicolumn{4}{|c|}{ After 1 month of PNT treatments } \\
\hline & & $\begin{array}{c}\mathrm{Ht} \\
(\mathrm{cm} / \text { plant })\end{array}$ & $\begin{array}{c}\text { Leaf } \\
\text { number } \\
\text { (plant) }\end{array}$ & $\begin{array}{l}\text { Flower } \\
\text { number } \\
\text { (plant) }\end{array}$ & $\begin{array}{c}\text { Leaf } \\
\text { chlorophyll }\end{array}$ & $\begin{array}{l}\text { Leaf area } \\
\left(\mathrm{m}^{2} / \text { plant }\right)\end{array}$ & $\begin{array}{l}\mathrm{SLW}^{\mathrm{w}} \\
\left(\mathrm{g} \cdot \mathrm{m}^{-2}\right)\end{array}$ & $\begin{array}{c}\text { Fruit } \\
\text { number } \\
\text { (plant) }\end{array}$ & $\begin{array}{c}\text { Fruit } \\
\text { size } \\
\text { (g/fruit) }\end{array}$ \\
\hline \multirow[t]{5}{*}{ Bigdena } & PNT9 & 110 & 15.1 & $9.8 \mathrm{~b}$ & 53.6 & 0.96 & 46.2 & 10.9 & $48.8 \mathrm{~b}$ \\
\hline & PNT11 & 113 & 15.0 & $14.7 \mathrm{a}$ & 50.4 & 1.18 & 47.9 & 12.3 & $63.3 \mathrm{~b}$ \\
\hline & PNT13 & 117 & 15.0 & $14.8 \mathrm{a}$ & 57.2 & 1.09 & 55.5 & 11.2 & $92.6 \mathrm{a}$ \\
\hline & PNT15 & 109 & 14.6 & $17.5 \mathrm{a}$ & 52.0 & 1.27 & 49.2 & 12.0 & $75.9 \mathrm{ab}$ \\
\hline & $\operatorname{LSD}_{0.05^{\mathrm{y}}}$ & - & - & 4.6 & - & - & - & - & 28.4 \\
\hline \multirow[t]{5}{*}{ Quest } & PNT9 & 104 & 16.7 & $9.0 \mathrm{~b}$ & 46.5 & 1.33 & 38.6 & 9.6 & 49.7 \\
\hline & PNT11 & 101 & 16.5 & $12.3 \mathrm{a}$ & 49.3 & 1.42 & 39.9 & 11.5 & 52.4 \\
\hline & PNT13 & 102 & 16.5 & $12.3 \mathrm{a}$ & 54.1 & 1.41 & 41.8 & 10.8 & 67.3 \\
\hline & PNT15 & 105 & 16.0 & $13.2 \mathrm{a}$ & 50.6 & 1.23 & 41.4 & 12.8 & 53.3 \\
\hline & $\operatorname{LSD}_{0.05^{\mathrm{y}}}$ & - & - & 1.3 & - & - & - & - & - \\
\hline \multirow[t]{5}{*}{ Clarance } & PNT9 & 125 & 16.6 & 17.2 & $55.9 \mathrm{~b}$ & 1.20 & 44.4 & 15.1 & 52.1 \\
\hline & PNT11 & 132 & 16.1 & 20.0 & $56.2 \mathrm{ab}$ & 1.43 & 45.2 & 15.0 & 54.6 \\
\hline & PNT13 & 134 & 16.0 & 20.8 & $60.0 \mathrm{a}$ & 1.16 & 57.4 & 13.9 & 60.1 \\
\hline & PNT15 & 132 & 15.7 & 17.2 & $59.2 \mathrm{ab}$ & 1.21 & 56.0 & 14.2 & 61.6 \\
\hline & $\operatorname{LSD}_{0.05^{\mathrm{y}}}$ & - & - & - & 3.9 & - & - & - & - \\
\hline \multirow[t]{5}{*}{ Conchita } & PNT9 & 120 & 19.0 & $50.5 \mathrm{~b}$ & 53.9 & 0.93 & $44.6 \mathrm{c}$ & 54.1 & 9.1 \\
\hline & PNT11 & 115 & 20.0 & $51.7 \mathrm{~b}$ & 53.9 & 1.01 & $54.6 \mathrm{~b}$ & 59.3 & 10.0 \\
\hline & PNT13 & 125 & 20.5 & $64.2 \mathrm{a}$ & 62.5 & 0.85 & $61.4 \mathrm{a}$ & 74.3 & 9.6 \\
\hline & PNT15 & 117 & 19.3 & $65.8 \mathrm{a}$ & 55.1 & 1.02 & $46.9 \mathrm{c}$ & 77.5 & 8.9 \\
\hline & $\operatorname{LSD}_{0.05^{\mathrm{y}}}$ & - & - & 7.5 & - & - & 6.7 & - & - \\
\hline \multirow[t]{8}{*}{ After 2 weeks } & Parameters & \multicolumn{2}{|c|}{ Cultivar } & \multicolumn{5}{|c|}{ Regression equation } & $R_{\mathrm{t}}^{2 \mathrm{x}}$ \\
\hline & Chlorophyll & \multicolumn{2}{|c|}{ Bigdena } & \multicolumn{5}{|c|}{$\mathrm{Y}=965.65-230.8557 \mathrm{PNT}+19.1298 \mathrm{PNT}^{2}-0.5195 \mathrm{PNT}^{3}$} & $0.75^{*}$ \\
\hline & & \multicolumn{2}{|c|}{ Clarance } & \multicolumn{5}{|c|}{$\mathrm{Y}=48.96+0.7178 \mathrm{PNT}$} & $0.45^{*}$ \\
\hline & $\mathrm{SLW}^{\mathrm{w}}$ & \multicolumn{2}{|c|}{ Conchita } & \multicolumn{5}{|c|}{$\mathrm{Y}=-210.12+42.9470 \mathrm{PNT}-1.7087 \mathrm{PNT}^{2}$} & $0.87 * *$ \\
\hline & & \multicolumn{2}{|c|}{ Clarance } & \multicolumn{5}{|c|}{$\mathrm{Y}=19.86+2.4816 \mathrm{PNT}$} & $0.44^{*}$ \\
\hline & Flower number & \multicolumn{2}{|c|}{ Bigdena } & \multicolumn{5}{|c|}{$\mathrm{Y}=-0.76+1.2095 \mathrm{PNT}$} & $0.79 * *$ \\
\hline & & \multicolumn{2}{|c|}{ Quest } & \multicolumn{5}{|c|}{$\mathrm{Y}=-201.94+50.1061 \mathrm{PNT}-3.8899 \mathrm{PNT}^{2}+0.1003 \mathrm{PNT}^{3}$} & $0.98 * *$ \\
\hline & & \multicolumn{2}{|c|}{ Conchita } & \multicolumn{4}{|c|}{$\mathrm{Y}=19.94+3.0792 \mathrm{PNT}$} & & $0.85^{* *}$ \\
\hline \multirow[t]{3}{*}{ After 1 month } & Fruit no. & \multicolumn{2}{|c|}{ Conchita } & \multicolumn{4}{|c|}{$\mathrm{Y}=10.85+4.4822 \mathrm{PNT}$} & & $0.79 * *$ \\
\hline & Fruit size & Bigc & & $\mathrm{Y}=-2.56$ & $739 \mathrm{PNT}$ & & & & $0.44^{*}$ \\
\hline & & Clar & & $\mathrm{Y}=35+$ & 6PNT & & & & $0.44^{*}$ \\
\hline
\end{tabular}

${ }^{\mathrm{z}}$ Data presented are the means of nine plants from the three replications; the treatment means followed by different letters are significantly different $(P \leq 0.05)$ according to a LSD test.

${ }^{\mathrm{y}} \mathrm{LSD}_{0.05}=$ least significant difference at $\alpha=0.05$; the separation of treatment means was only conducted when the PNT effect in the analysis of variance was significant $(P \leq 0.05)$, i.e., protected LSD test. There was no significant PNT effect $(P>0.05)$ when the means were not separated by a LSD test.

${ }^{\mathrm{x}}$ The $*$ or $* *$ indicates the regression is significant $(0.05 \geq P>0.01)$ or very significant $(P \leq 0.01)$, respectively.

${ }^{\mathrm{w}} \mathrm{SLW}=$ specific leaf weight.

$\mathrm{PNT}=$ pre-night temperature

flower number $(P \leq 0.01)$. This was most likely the result of the cultivar difference in tolerance to low temperature. Cherry tomato 'Conchita' seemed to be the most sensitive cultivar to low temperature because its flower number was reduced when PNT was below $13^{\circ} \mathrm{C}$, whereas cluster tomato 'Clarance' was the least sensitive because its flower number was unaffected (Table 3). The flower number in both 'Bigdena' and 'Quest' was reduced by the lowest PNT (PNT9), indicating PNT9 was below their low temperature tolerance threshold.

Biomass and biomass partition. Only a very small portion $(4 \%)$ of biomass is partitioned into roots in mature greenhouse tomato plants (Khan and Sagar, 1969). Therefore, only the above-ground biomass was considered in this study. The biomass increased with increasing PNT at the low range of PNT, peaked at $\approx 13{ }^{\circ} \mathrm{C}$ PNT $\left(13.7\right.$ and $13{ }^{\circ} \mathrm{C}$ for 'Bigdena' and 'Conchita', respectively, obtained by solving the first derivative of the regression equations in Figure 1), and then declined at high PNT in 'Bigdena' and 'Conchita' (Fig. 1). In 'Quest' and 'Clarance', the response of biomass to PNT was much smaller (not significant, $P>0.05$ ), although the trend was similar (Fig. 1). Photosynthesis is the main source of biomass formation, whereas maintenance respiration is responsible for most of biomass exhaustion. Leaf photosynthetic capacity and respiration rates at the highest PNT (PNT15) were higher than those at the lowest PNT (PNT9) in both 'Bigdena' and 'Conchita' (Table 2). Therefore, the biomass increasing with increasing PNT at a low range of PNT was most likely the result of the increased photosynthetic capacity, whereas the decline at high PNT such as PNT15 might be the result of excessive respiration. Therefore, just as discussed on specific leaf weight, PNT at $\approx 13{ }^{\circ} \mathrm{C}$ might have allowed for the proper balance between photoassimilate generation (photosynthesis) and consumption (respiration) to achieve the highest photoassimilate accumulation in 'Bigdena' and 'Conchita'.

The fruit dry weight showed the same trend as the above-ground plant biomass in 'Bigdena' (Table 4). The biomass partition to stem decreased at PNT11 and PNT13 in 'Bigdena' with the lowest value at $12.9{ }^{\circ} \mathrm{C}$ PNT (obtained by the solving the first de- rivative of its regression equation in Table 4), which indicated the biomass partitioning to fruit or leaves or both could have increased at $12.9^{\circ} \mathrm{C}$ PNT. However, the biomass partition to leaves was the lowest at PNT13; that left only one possibility, i.e., there was an increase in biomass partition to fruit at $\approx 13{ }^{\circ} \mathrm{C}$ PNT. The partition to fruit was the highest at $12.9{ }^{\circ} \mathrm{C}$ (obtained by solving the first derivative of its non-significant regression equation, $P>0.05$ ), which at least partially confirmed this possibility. Therefore, there was a potential increase in biomass partition to fruit at $12.9{ }^{\circ} \mathrm{C}$ PNT. The difficulty in precise determination of fruit dry weight (larger experimental error) might have prevented the detection of this PNT effect on biomass partition to fruit in 'Bigdena'. The PNT at $12.9^{\circ} \mathrm{C}$ might have changed plant growth balance in favor of generative growth in 'Bigdena'.

Many genetic and environmental factors affect the source and sink strength, biomass partition, and growth balance of greenhouse tomatoes (Heuvelink and Dorais, 2005). Environmental conditions enhancing source strength such as strong light and high 


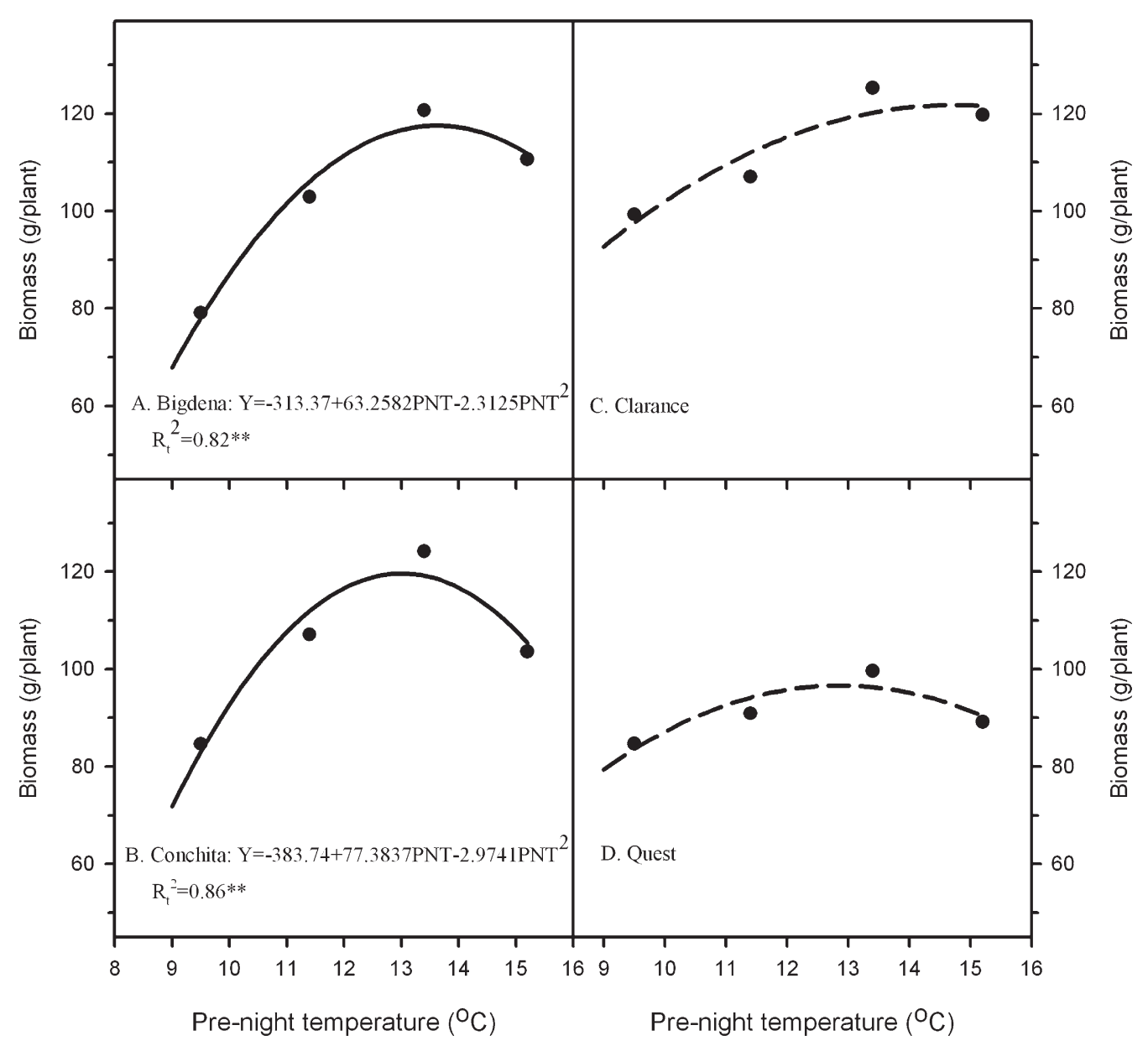

Fig. 1. Biomass (total above-ground dry matter, after 1 month of temperature treatments) of tomato cvs. Bigdena (A), Conchita (B), Clarance (C), and Quest (D) grown under four temperature integration treatments with low pre-night temperature $\left(\mathrm{PNT},{ }^{\circ} \mathrm{C}\right)$. The solid line indicates the regression is significant $(P \leq$ $0.05)$, whereas the dash line indicates it is not significant $(P>0.05)$.

concentration of $\mathrm{CO}_{2}$ tend to increase the biomass distribution to fruit and change plant growth balance in favor of generative growth (Challa et al., 1995; Heuvelink and Dorais, 2005). Because of the low temperature and weak light conditions, tomato plants are usually vegetative during the winter in cold regions (OMAFRA, 2005). Raising greenhouse temperature might change plant growth balance toward generative growth (De Koning, 1994). However, it would also lead to higher energy consumption. With a PNT of $\approx 13{ }^{\circ} \mathrm{C}$, the plant growth in 'Bigdena' could also be changed in favor of generative growth without raising 24-h temperature, i.e., without more energy use.

The biomass partition to fruit increased linearly with high PNT in 'Quest', whereas it was unaffected by PNT treatments in 'Clarance' (Table 4). This difference in biomass partition to fruit between 'Quest' and 'Clarance' could be the result of a genetic difference. There is a large genetic difference among tomato lines on vegetative and generative growth balance (biomass partition) under the low-temperature and weak light conditions as experienced during the winter in greenhouses (Lindhout, 2005). 'Quest' is a very vegetative cultivar, which usually requires high temperature to promote generative growth. In contrast, 'Clarance' is an early cultivar with balanced vegetative and generative growth and thus its biomass partition was unaffected by the PNT treatments.

Fruit yield. The PNT treatments significantly affected the total fruit yield (fresh weight) in 'Bigdena' and 'Conchita' but not in 'Quest' and 'Clarance' (Fig. 2). Total fruit yield increased with increasing PNT at low range of PNT and then peaked at 13.8 and $14.9{ }^{\circ} \mathrm{C}$ PNT for 'Bigdena' and 'Conchita', respectively (Fig. 2). The PNT treatments did not affect the number of fruit but fruit size in 'Bigdena' (Table 3) and thus the difference on fruit yield was the result of the difference in fruit size (fresh weight per fruit). The PNT treatments did not change the fruit size in 'Conchita' (Table 3); its yield increase with high PNT was mostly the result of higher fruit number (its fruit number increased linearly with high PNT; Table 3). Like in commercial production, the fruit clusters of beefsteak and cluster tomatoes were pruned to five fruit per cluster (to maintain good fruit grades/size), whereas the clusters were not pruned in the cherry tomato cv. Conchita. Therefore, the PNT influence on fruit yield was mainly achieved through affecting fruit growth of individual fruit (fruit size) in beefsteak tomato cv. Bigdena and the number of fruit in the cherry tomato $\mathrm{cv}$. Conchita.

Fruit disorder. BER is a fruit physiological disorder associated with the local $\mathrm{Ca}^{2+}$ deficiency in the blossom end of the fruit (Ho et al., 1993). It can cause economic loss because BER fruit is not marketable. The lowest PNT treatment (PNT9) resulted in the appearance of BER fruit $(P<0.05)$ in 'Bigdena' (49.9 g or 1.1 fruit/plant), 'Quest' (14.6 g or 0.25 fruit/plant), and 'Clarance' (43.7 g or 0.67 fruit/plant) but not in cherry tomato $\mathrm{cv}$. Conchita ( $0 \mathrm{~g}$ or 0 fruit/plant). There was no BER fruit ( $0 \mathrm{~g}$ or 0 fruit/plant) caused by other PNT treatments. BER usually appears when some kind of environmental stress occurs (Saure, 2001). Low and high temperature may induce BER (Ho et al., 1993). There is very limited information available on the relationship between low night temperature and BER occurrence and most of the research conducted previously was based on constant low night temperature instead of dynamic low temperature. It was determined by this study that $3 \mathrm{~h}$ of $9{ }^{\circ} \mathrm{C}$ $\left(9.4^{\circ} \mathrm{C}\right.$ to be exact; Table 1$)$ induced BER in beefsteak and cluster greenhouse tomatoes. Cherry tomato has much smaller fruit than beefsteak and cluster tomatoes, which might make it easy for the $\mathrm{Ca}^{2+}$ to reach the blossom end and thus has a higher tolerance to BER. Therefore, no incidence of BER was observed in cherry tomato cv. Conchita.

Optimum pre-night temperature for $d y$ namic temperature integration. The optimum 
Table 4. Fruit dry weight and biomass partition of four tomato cultivars grown with different temperature treatments. ${ }^{\mathrm{y}}$

\begin{tabular}{|c|c|c|c|c|c|}
\hline \multirow[b]{2}{*}{ Cultivar } & \multirow[b]{2}{*}{ Treatment } & \multirow{2}{*}{$\begin{array}{c}\text { Fruit dry } \\
\text { wt (g/plant) }\end{array}$} & \multicolumn{3}{|c|}{ Biomass allocation (\%) } \\
\hline & & & Stem & Leaf & Fruit \\
\hline \multirow[t]{5}{*}{ Bigdena } & PNT9 & $18.0 \mathrm{~b}$ & $21.6 \mathrm{a}$ & 55.9 & 22.5 \\
\hline & PNT11 & $27.1 \mathrm{ab}$ & $18.2 \mathrm{~b}$ & 56.3 & 25.5 \\
\hline & PNT13 & $38.0 \mathrm{a}$ & $18.5 \mathrm{~b}$ & 51.2 & 30.3 \\
\hline & PNT15 & $28.0 \mathrm{ab}$ & $19.4 \mathrm{ab}$ & 55.9 & 24.7 \\
\hline & $\operatorname{LSD}_{0.05^{y}}$ & 11.3 & 2.3 & - & - \\
\hline \multirow[t]{5}{*}{ Quest } & PNT9 & 17.9 & 18.7 & 60.3 & 21.0 \\
\hline & PNT11 & 18.7 & 17.2 & 62.3 & 20.5 \\
\hline & PNT13 & 25.0 & 16.8 & 58.2 & 25.1 \\
\hline & PNT15 & 23.7 & 16.4 & 57.0 & 26.6 \\
\hline & $\operatorname{LSD}_{0.05^{y}}$ & - & - & - & - \\
\hline \multirow[t]{5}{*}{ Clarance } & PNT9 & 27.7 & 19.7 & 52.7 & 27.6 \\
\hline & PNT11 & 28.4 & 17.8 & 55.6 & 26.6 \\
\hline & PNT13 & 34.8 & 19.0 & 54.1 & 26.9 \\
\hline & PNT15 & 34.6 & 17.6 & 54.7 & 27.7 \\
\hline & $\operatorname{LSD}_{0.05^{y}}$ & - & - & - & - \\
\hline \multirow[t]{5}{*}{ Conchita } & PNT9 & 26.4 & 20.0 & 49.0 & 30.9 \\
\hline & PNT11 & 30.9 & 19.6 & 51.8 & 28.7 \\
\hline & PNT13 & 47.1 & 19.4 & 42.2 & 38.4 \\
\hline & PNT15 & 38.5 & 17.0 & 45.9 & 37.2 \\
\hline & $\operatorname{LSD}_{0.05^{y}}$ & - & - & - & - \\
\hline Parameters & Cultivar & \multicolumn{3}{|c|}{ Regression equation } & $R_{\mathrm{t}}^{2 \times}$ \\
\hline \multirow[t]{2}{*}{ Fruit dry matter } & Bigdena & \multicolumn{3}{|c|}{$\mathrm{Y}=-193.05+34.5543 \mathrm{PNT}-1.3113 \mathrm{PNT}^{2}$} & $0.66^{*}$ \\
\hline & Quest & \multicolumn{3}{|c|}{$\mathrm{Y}=5.5691+1.2628 \mathrm{PNT}$} & $0.79 * *$ \\
\hline To stem (\%) & Bigdena & \multicolumn{3}{|c|}{$\mathrm{Y}=67.84-7.7456 \mathrm{PNT}+0.3008 \mathrm{PNT}^{2}$} & $0.68^{*}$ \\
\hline To fruit $(\%)$ & Quest & \multicolumn{3}{|c|}{$\mathrm{Y}=9.30+1.1308 \mathrm{PNT}$} & $0.60^{*}$ \\
\hline
\end{tabular}

${ }^{\mathrm{z}}$ Data presented are the means of nine plants from the three replications; the treatment means followed by different letters are significantly different $(P \leq 0.05)$ according to a LSD test.

${ }^{y_{L S D}}{ }_{0.05}=$ least significant difference at $\alpha=0.05$; the separation of treatment means was only conducted when the PNT effect in the analysis of variance was significant $(P \leq 0.05)$, i.e., protected LSD test. There was no significant PNT effect $(P>0.05)$ when the means were not separated by a LSD test.

${ }^{\mathrm{x}}$ The $*$ or $* *$ indicates the regression is significant $(0.05 \geq P>0.01)$ or very significant $(P \leq 0.01)$, respectively.

PNT $=$ pre-night temperature

low PNT for the dynamic temperature integration should be able to increase early fruit yield without increasing energy consumption or reduce energy consumption without compromising yield and quality. From an energysaving point of view, the lower the PNT is, the higher energy savings can be achieved. Therefore, the task for determining optimum PNT is to find the lowest PNT that maximizes fruit yield and quality. This is largely dependent on the tolerance to low temperature. The tolerance to low temperature and the optimum temperature for plant growth and fruit yield varies with cultivars (Gary, 1989; Seginer et al., 1994). Three main types (beefsteak, cluster, and cherry) of greenhouse tomatoes, including two beefsteak cultivars with different growth habits and temperature requirements, were used in this study to ensure the finding is applicable for a wide range of tomatoes. The lowest PNT that maximized fruit yield was 13.8 and $14.9^{\circ} \mathrm{C}$ for 'Bigdena' and 'Conchita', respectively. Therefore, the optimum low PNT for the new dynamic temperature control strategy, at least based on fruit yield, was 13.8 and $14.9^{\circ} \mathrm{C}$ for 'Bigdena' and 'Conchita', respectively. The fruit yield response to PNT in 'Quest', although not significant, showed a similar trend (optimum PNT, obtained by solving the first derivative of its non-significant regression equation was 13.6 ${ }^{\circ} \mathrm{C}$; Fig. 2). The fruit yield of 'Clarance' was not reduced by PNT9 or PNT11, indicating
'Clarance' was more tolerant to low temperature. The high low-temperature tolerance in 'Clarance' was also supported by the lack of response in its flower number to low PNT (Table 3). Therefore, the optimum PNT for 'Clarance' can be lower than $13{ }^{\circ} \mathrm{C}$ if it does not compromise fruit quality. A $9.4{ }^{\circ} \mathrm{C}$ PNT (Table 1) was too low because it induced BER. This study did not investigate the effects of temperature on fruit ripening and other quality attributes. Based on the recent review on tomato postharvest biology and handling by Saltveit (2005), a temperature no lower than 12 ${ }^{\circ} \mathrm{C}$ is needed to prevent any undesirable effect on fruit quality. Therefore, the optimum low PNT temperature for dynamic temperature integration is $13.8^{\circ} \mathrm{C}$ for 'Bigdena' and $14.9^{\circ} \mathrm{C}$ for 'Conchita', whereas 12 to $13{ }^{\circ} \mathrm{C}$ may be used for 'Clarance'.

Mechanism for temperature integration with low pre-night temperature. The biomass peaked at $\approx 13{ }^{\circ} \mathrm{C}\left(13.7\right.$ and $13{ }^{\circ} \mathrm{C}$ for 'Bigdena' and 'Conchita', respectively). High PNT (PNT15) increased leaf photosynthesis, whereas low PNT (PNT9) reduced leaf respiration (Table 2). The PNT13 $\left(13.3^{\circ} \mathrm{C}\right.$ actual air temperature) also had the highest specific leaf weight in 'Conchita' (Table 3). Therefore, the PNT at $\approx 13{ }^{\circ} \mathrm{C}$ might have allowed for high photosynthesis for photoassimilate generation and low respiration for photoassimilate conservation and thus accumulated the highest biomass, which have pro- vided the foundation for better plant growth and high fruit yield.

The potential higher biomass partition to fruit at $12.9{ }^{\circ} \mathrm{C}$ PNT might also have contributed to the higher yield at $13.8{ }^{\circ} \mathrm{C}$ in 'Bigdena'. The PNT at $\approx 13{ }^{\circ} \mathrm{C}$ did not result in higher biomass allocation to fruit in 'Clarance' and 'Conchita'. 'Bigdena' had much larger fruit size than 'Clarance' and 'Conchita' (Table 3). With larger fruit, the buffer capacity of the fruit is larger, which will reduce the speed of fruit temperature decline when there is a sharp temperature drop in air temperature. With a low pre-night temperature pulse (fast drop to $13.5{ }^{\circ} \mathrm{C}$ and then quickly restored to normal night temperature of $18{ }^{\circ} \mathrm{C}$ ), higher fruit temperature (relative to leaf temperature) was achieved in 'Bigdena' (Hao et al., 2008). The growth rates of plant organs are directly related to organ temperature (Pearce et al., 1993); thus, this higher fruit temperature promoted fruit growth and resulted in high early fruit yield (Hao et al., 2008) in 'Bigdena'. The fruit to leaf temperature difference might be smaller with cultivars with small fruit size such as 'Clarance' and 'Conchita'. Therefore, promotion of biomass allocation to fruit by PNT at $\approx 13{ }^{\circ} \mathrm{C}$ was much smaller in 'Clarance' and 'Conchita'. The biomass allocation to fruit decreased linearly with low PNT in 'Quest' (Table 4). 'Quest' is a vegetative cultivar with poor tolerance to low temperature (which has been abandoned in commercial production in Ontario, Canada); the low PNT might have limited transportation of photoassimilates to fruit. With proper low PNT and suitable cultivars, especially tomatoes with large fruit size, the biomass allocation to fruit could be increased, which should further contribute to high fruit yield.

The optimum PNT for biomass was $13^{\circ} \mathrm{C}$ in cherry tomato 'Conchita', whereas optimum PNT for fruit yield was $14.9{ }^{\circ} \mathrm{C}$. Its flower development had the least tolerance to low PNT among the four cultivars (Table 3 ). Because the fruit size in the cherry tomato was relatively constant, the reduction in flower development rate might have limited its fruit yield response to low PNT and raised the optimum PNT for fruit yield to $14.9^{\circ} \mathrm{C}$.

Dynamic temperature integration with low PNT used similar energy during the winter and less energy in early spring in comparison with conventional temperature integration strategy without low PNT (Hao et al., 2008). Therefore, the dynamic temperature integration with proper low PNT can be an effective temperature control strategy for improving early fruit yield and energy use efficiency for some cultivars such as 'Bigdena'.

In summary, the optimum low PNT for dynamic temperature integration for greenhouse tomato cv. Bigdena and Conchita was 13.8 and $14.9^{\circ} \mathrm{C}$, respectively, whereas it can be lowered to $12{ }^{\circ} \mathrm{C}$ for 'Clarance'. The PNT at $\approx 13{ }^{\circ} \mathrm{C}$ might have allowed for the proper balance between the high photosynthesis for photoassimilate generation and the low respiration for photoassimilate conservation and thus accumulated the highest biomass. 


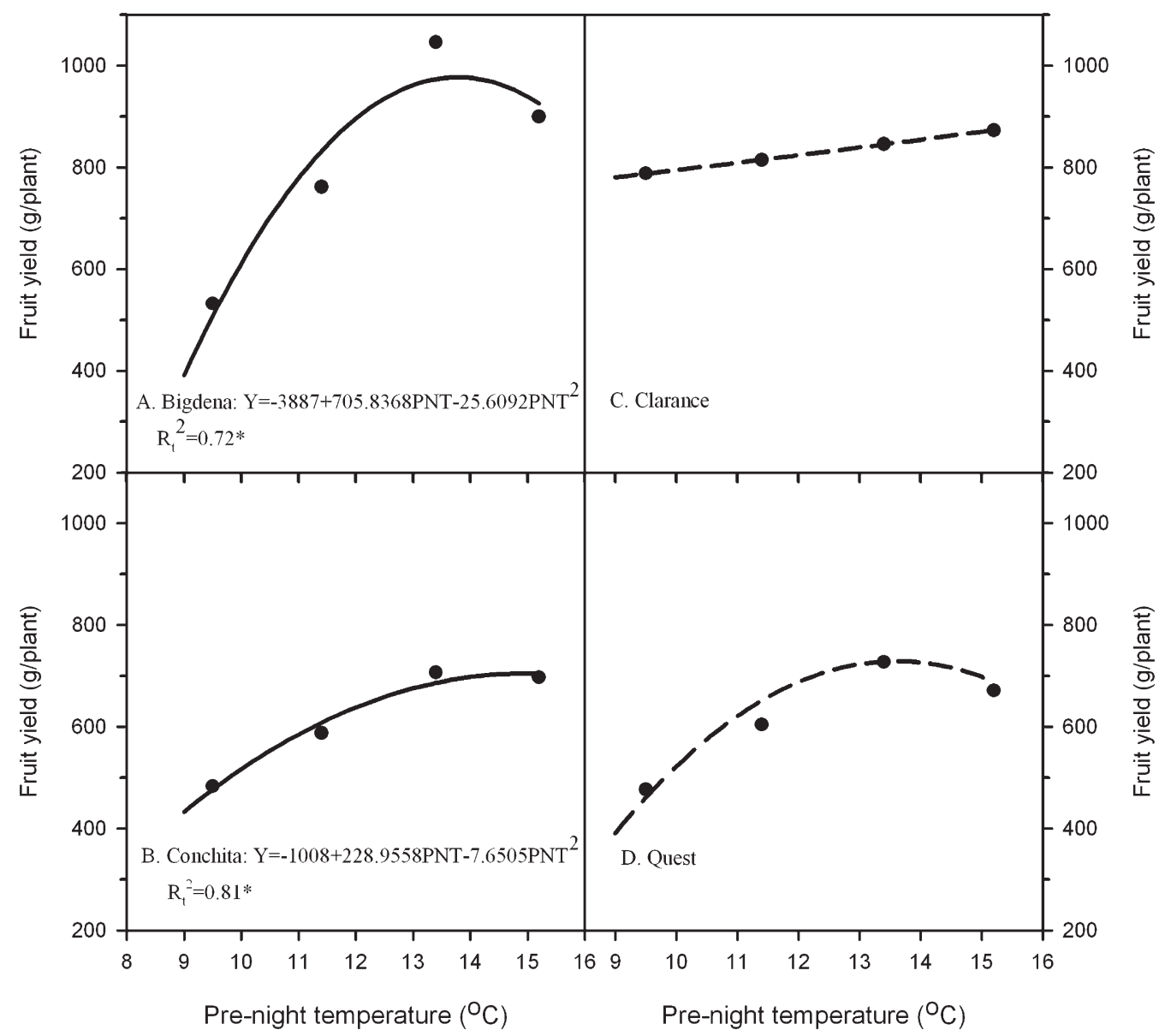

Fig. 2. Fruit yield (after 1 month of temperature treatments) of tomato cvs. Bigdena (A), Conchita (B), Clarance (C), and Quest (D) grown under four temperature integration treatments with low pre-night temperature $\left(\mathrm{PNT},{ }^{\circ} \mathrm{C}\right)$. The solid line indicates the regression is significant $(P \leq 0.05)$, whereas the dash line indicates it is not significant $(P>0.05)$.

Because the dynamic temperature integration with proper low PNT uses similar or less energy than a conventional temperature integration strategy without low PNT (Hao et al., 2008), the new temperature strategy can be an effective tool for improving early fruit yield and energy use efficiency in greenhouse tomato production.

\section{Literature Cited}

Bot, G.P.A. 2001. Developments in indoor sustainable plant production with emphasis on energy saving. Comput. Electron. Agr. 30:151-165.

Chalabi, Z.S., B.J. Bailey, and D.J. Wilkinson. 1996. A real-time optimal control algorithm for greenhouse heating. Comput. Electron. Agr. 15:1-13.

Challa, H., E. Heuvelink, and U. Van Meeteren. 1995. Crop growth and development, p. 62-84. In: Bakker, J.C., G.P.A. Bot, H. Challa, and N.J. Van de Braak (eds.). Greenhouse climate control: An integrated approach. Wageningen Pers, Wageningen, The Netherlands.

De Koning, A.N.M. 1990. Long term temperature integration of tomato - Growth and development under alternative temperature regimes. Sci. Hort. 45:117-127.

De Koning, A.N.M. 1992. Effects of temperature on development rate and length increase of tomato, cucumber and sweet pepper. Acta Hort. 305:51-55.

De Koning, A.N.M. 1994. Development and dry matter distribution in glasshouse tomato: A quantitative approach. $\mathrm{PhD}$ diss., Wageningen Univ., Wageningen, The Netherlands.

Diaz-Perez, J.C. and K.D. Batal. 2002. Colored plastic film mulches affect tomato growth and yield via changes in root-zone temperature. J. Amer. Soc. Hort. Sci. 127:127-136.

Gary, C. 1989. Interest of a carbon balance model for on-line growth control: The example of daylight and diurnally fluctuant temperatures. Plant Physiol. 76:694-699.

Hao, X., M.S. Borhan, and J.M. Zheng. 2008. Effects of temperature integration regimes with low prenight temperatures on energy consumption, microclimate, and fruit yield in early greenhouse tomato production. Acta Hort. 801:473-478.

Heuvelink, E. and M. Dorais. 2005. Crop growth and yield, p. 84-144. In: Heuvelink, E. (ed.). Tomatoes. CABI International, Wallingford, Oxfordshire, UK.

Ho, L.C., R. Belda, M. Brown, J. Andrews, and P. Adams. 1993. Uptake and transport of calcium and the possible causes of blossom-end rot in tomato. J. Expt. Bot. 44:509-518.

Hurd, R.G. and C.J. Graves. 1984. The influence of different temperature patterns having the same integral on the earliness and yield of tomatoes. Acta Hort. 148:547-554.

Jensen, M.H. and A.J. Malter. 1994. Protected agriculture-A global review. World Bank tech paper no. 253. The World Bank, Washington, DC.

Khan, A. and G.R. Sagar. 1969. Alternation of the pattern of distribution of photosynthetic products in the tomato by manipulation of the plant Ann. Bot. (Lond.) 33:753-762.
Korner, O., M.J. Bakker, and E. Heuvelink. 2004. Daily temperature integration: A simulation study to qualify energy consumption. Bios. Eng. 87:333-343.

Langhans, R.W., M. Wolfe, and L.D. Albright 1985. Use of average night temperatures for plant growth for potential energy savings. Acta Hort. 115:31-36.

Lindhout, P. 2005. Genetics and breeding, p. 2152. In: Heuvelink, E. (ed.). Tomatoes. CABI International, Wallingford, Oxfordshire, UK.

Miller, W.B., R.W. Langhans, and L.D. Albright. 1985. Plant growth under averaged day night temperature. Acta Hort. 174:313-320.

Ontario Ministry of Agriculture, Food and Rural Affairs. 2004. Greenhouse tomato. Grading and packing manual. Food Safety and Environment Division, Regulation 378:90.

OMAFRA. 2005. Growing greenhouse vegetables, Publication 371. Queen's Printer for Ontario, Toronto, Canada.

Ozkan, B., A. Kurklu, and H. Akcaoz. 2004. An input-output energy analysis in greenhouse vegetable production: A case study for Antalya region of Turkey. Biomass Bioenergy 26:8995.

Papadopoulos, A.P. and X. Hao. 2000a. Effects of day and night air temperature in early season on growth, productivity and energy use of spring tomato. Can. J. Plant Sci. 81:303-311.

Papadopoulos, A.P. and X. Hao. 2000b. Effects of day and night air temperature on growth, productivity and energy use of long English cucumber. Can. J. Plant Sci. 80:143-150. 
Papadopoulos, A.P. and N. Liburdi. 1989. The Harrow Fertigation Manager, a computerized multifertilizer injector. Acta Hort. 260:255266.

Pearce, B.D., R.I. Grange, and K. Hardwick. 1993. The growth of young tomato fruit. I. Effects of temperature and irradiance on fruit grown in controlled environments. J. Hort. Sci. 68:1-11.

Pollet, B., K. Steppe, P. Dambre, M.V. Labeke, and R. Lemeur. 2009. Temperature integration of Hedera helix L.: Quality aspects and growth response. Sci. Hort. 120:89-95.
Rijsdijk, A.A. and J.V.M. Vogelezang. 2000. Temperature integration on a 24-h base: A more efficient climate control strategy. Acta Hort. 519:163-169.

Saltveit, M.E. 2005. Postharvest biology and handling, p. 305-324. In: Heuvelink, E. (ed.). Tomatoes. CABI International, Wallingford, Oxfordshire, UK.

Saure, M.C. 2001. Blossom-end rot of tomato (Lycopersicon esculentum Mill.) - A calcium or a stress-related disorder? Sci. Hort. 90:193-208.

Seginer, I., C. Gary, and M. Tchamitchian. 1994. Optimal temperature regimes for a greenhouse crop with a carbohydrate pool: A model study. Sci. Hort. 60:55-80.

Statistics Canada. 2005. Greenhouse, sod and nursery industries, Catalogue No. 22-202XIB.

Van den Berg, G.A., F. Buwalda, and E.C. Rijpsma. 2001. Practical demonstration of multiday temperature integration. Applied Plant Research, Wageningen UR, The Netherlands.

Wittwer, S.H. and N. Castilla. 1995. Protected cultivation of horticultural crops worldwide. HortTechnology 5:6-23. 